\title{
O Trabalho no Cultivo Orgânico de Frutas: uma Abordagem Ergonômica
}

Sandra Francisca Bezerra Gemma

Roberto Funes Abrahão²

Laerte Idal Sznelwar ${ }^{2}$

\section{Aspects of the Work on the Organic Fruit Cultivation: an Ergonomic Approach}

\footnotetext{
'M. Sc. do Departamento de Engenharia de Produção da Escola Politéenica da Universidade de São Paulo

${ }^{2}$ Doutores do Departamento de Engenharia de Produção da Escola Politécnica da Universidade de São Paulo
}

A agricultura orgânica tem sido apontada como uma forma de cultivo sustentável do ponto de vista ecológico, econômico e social. No entanto, não se encontram pesquisas sobre a relação saúde-trabalho na agricultura orgânica, não sendo possível afirmar que a eliminação dos riscos toxicológicos do sistema convencional seja suficiente para garantir a saúde dos agricultores.

Esta pesquisa tem como objetivo principal a compreensão das dificuldades encontradas na execução do trabalho na produção orgânica de frutas. Para tanto, foi realizado um estudo de caso em um sítio de cultivo orgânico de frutas, aplicando o método da Análise Ergonômica do Trabalho (AET). Tarefas manuais freqüentes no cultivo orgânico, como o ensacamento de frutas, executadas sob pressão temporal, podem colocar em risco a saúde dos agricultores por demandarem esforço físico considerável, posturas desconfortáveis e movimentos repetitivos.

Palavras-chave: fruticultura orgânica, ergonomia, tecnologia adaptada.

The main purpose of this research is the comprehension of the difficulties related to the work on the organic production of fruits. To achieve this subject, a case study was accomplished on a ranch dedicated to the cultivation of organic fruits. The Ergonomic Method derived from the French/Belgium School, which allows the understanding and transformation of the work through the step by step analysis of actual working conditions, was used as a base to support all the ergonomic analysis of the work performed. It is important to emphasize that some of the manual tasks, more often observed on an organic plantation, can expose the workers' health to several injuries, as they demand considerable physical effort, uncomfortable postures and repetitive movements that, reinforced by the timing pressure issue, can generate musculoskeletal problems.

Weeding, manual grading and fruits bagging, performed to control pests and diseases, are a good example of these type of tasks.

Keywords: organic fruticulture, ergonomics, adapted technology. 


\section{Introdução}

A agricultura orgânica tem sido apontada como uma forma de cultivo sustentável dos pontos de vista ecológico, econômico e social (Ehlers, 1999). A importância econômica da produção orgânica é crescente, tendo movimentado no mundo US\$ 10 bilhões em 1997 e US\$ 90 milhões no Brasil, em 1999; a maior parte da produção é do tipo familiar, representando 90\% do total (Chaim, 2002; Darolt, 2002; Ormond et al., 2001). Partindo de uma visão técnica, econômica e ecológica, diversas pesquisas têm sido feitas neste segmento (Darolt, 2002), no entanto, não se encontram pesquisas sobre a relação saúdetrabalho na agricultura orgânica, não sendo possível afirmar que a eliminação dos riscos toxicológicos do sistema convencional seja suficiente para garantir a saúde dos agricultores.

A ergonomia fornece elementos para o conhecimento dos riscos envolvidos nas atividades de trabalho, sendo, portanto, de bastante valia na agricultura, setor que comporta grande variedade de riscos (Alves Filho, 1999; Jafry, 2000; Pinzke, 1997; Wisner, 1994). Supõe-se que: a gestão da produção orgânica seja bastante complexa por envolver uma multiplicidade de cultivos; o processo de certificação do manejo orgânico traga tarefas adicionais para os agricultores; exista falta de tecnologia específica; e, por último, que exista um grande número de tarefas manuais necessárias para substituir o uso de produtos químicos convencionais e a mecanização na produção, solicitando um maior número de pessoas.

Diante do exposto, decidiu-se fazer um estudo de caso utilizando o método da Análise Ergonômica do Trabalho (AET) em uma produção orgânica de frutas do tipo familiar a fim de melhor compreender as dificuldades encontradas na execução do trabaIho, explorando questões ligadas à gestão da produção, ao processo de certificação, à tecnologia disponível e às tarefas manuais.

\section{Material e métodos}

Foi utilizado o método denominado Análise Ergonômica do Trabalho (AET), oriundo da escola franco-belga de ergonomia que se baseia na análise de situações reais de trabalho, possibilitando a compreensão e a transformação das mesmas (Guérin et al., 2001).

A pesquisa de campo foi realizada em uma empresa do tipo familiar com 4 hectares de produção orgânica de frutas, situada em Valinhos-SP, na qual trabalhavam doze pessoas (produtores, meeiros, diaristas, entre outros), e contou com as seguintes etapas: coleta de dados gerais da empresa e da população, consulta de documentos, entrevistas abertas e semi-estruturadas, observações diretas, registros através de filmagem e fotos e observações sistemáticas de tarefas específicas.

\section{Resultados e discussão}

O principal produto do sítio em questão é a goiaba branca, que corresponde a $29 \%$ do volume total produzido, seguida pelo pêssego, com $16 \%$, pelo morango e pela seriguela, com $11 \%$, pela goiaba vermelha, com $5 \%$, e pelos demais produtos, com $28 \%$. Algumas tarefas fatigantes são realizadas com maior freqüência, como, por exemplo, a capina manual em substituição aos praguicidas convencionais. Segundo um dos agricultores, há muitas atividades diferentes, o que dificulta o domínio técnico dos cultivos: "[...] não somos especialistas em nada, pois temos que cultivar um grande número de variedades". Essa variabilidade de cultivos fica evidente ao se constatar que em apenas 4ha. de área são produzidos mais de trinta $\mathrm{e}$ oito itens de fruticultura e vinte de horticultura.

Com relação à certificação da produção, constata-se o acréscimo de tarefas relacionadas: ao destino de resíduos domésticos e da produção; à necessidade de organização da propriedade, tendo locais específicos para embalagens e insumos, entre outros; ao controle do uso de implementos, como o arado, - que conduz à utilização de descompactadores naturais, como a adubação verde; à apresentação de análises de solo periódicas; à exigência de preenchimento de relatórios e planilhas detalhadas; à implantação 
e à manutenção de cerca viva a fim de oferecer uma barreira natural para evitar a contaminação da produção por insumos utilizados pelos vizinhos.

Não existem, no mercado, equipamentos e ferramentas apropriados ao manejo orgânico, demandando adaptações, como os exemplos mostrados na Tabela 1 e ilustrados nas Figuras 1, 2, 3, 4, e 5. Vale ressaltar que, muitas vezes, as adaptações funcionam de modo precário, podendo colocar em risco a saúde do trabalhador.

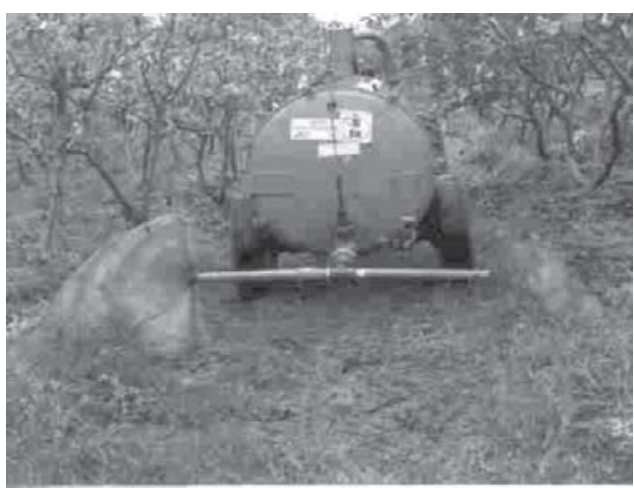

Figura 1 Chorumeira com adaptação em "T" durante pulverização.

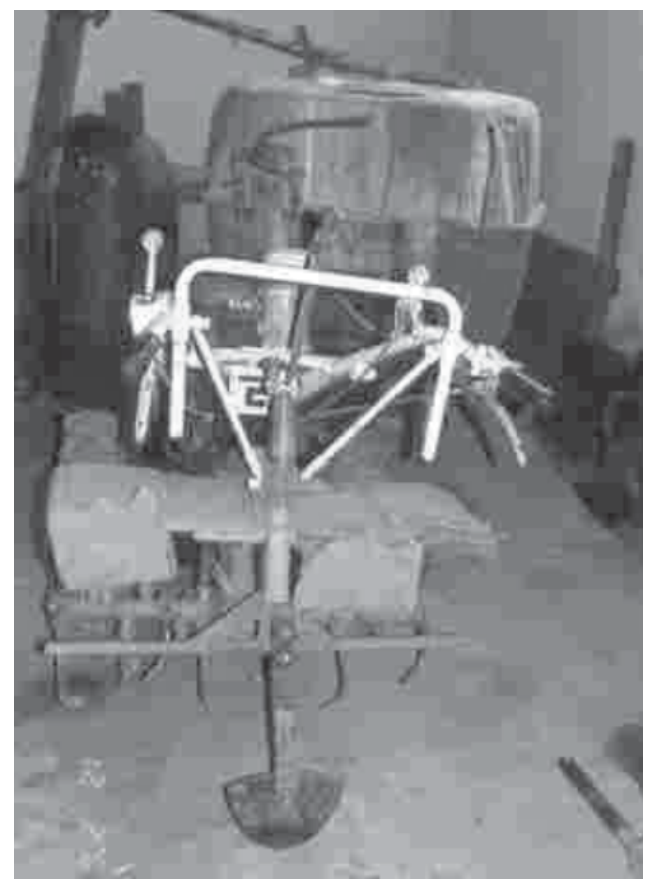

Figura 2 Microtrator Tobatta com adaptação do bico riscador.

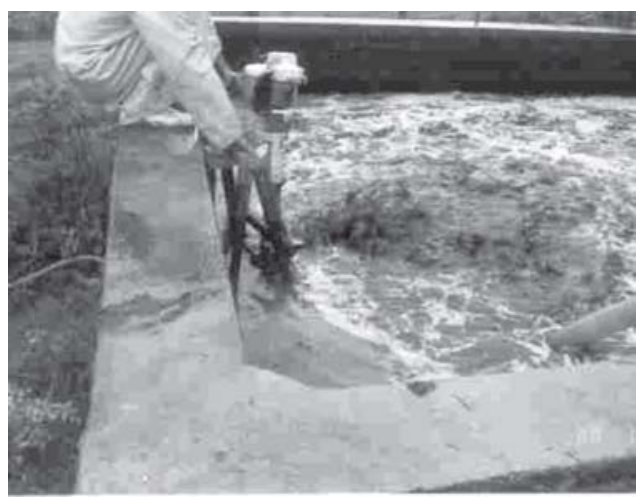

Figura 3 Motoserra adaptada com hélice de barco para mistura de chorume.

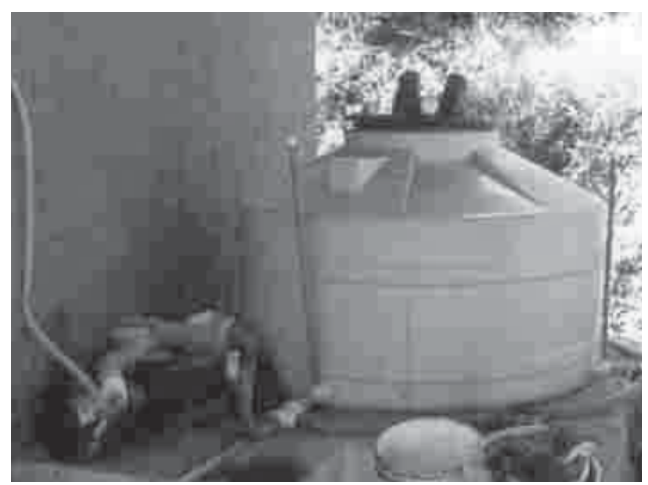

Figura 4 Aerador - fermentador adaptado.

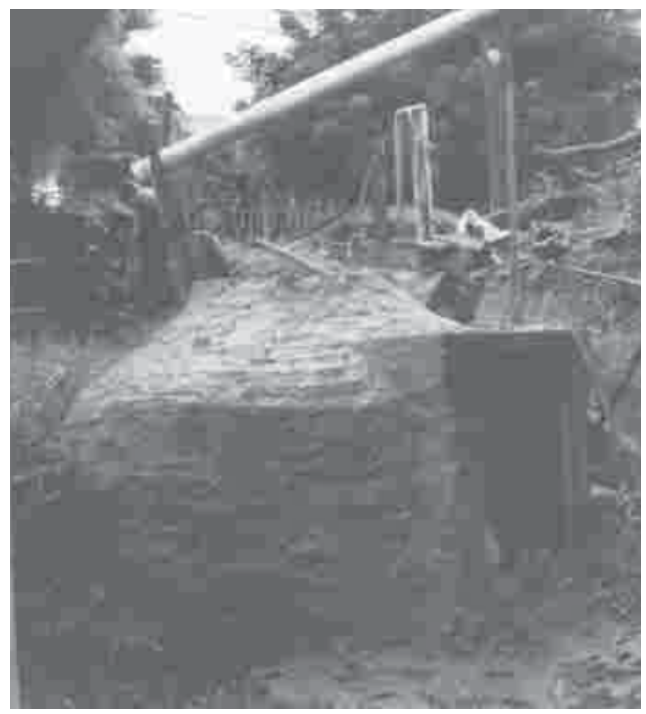

Figura 5 Forno de barro para obtenção de ácido pirolenhoso. 
Tabela 1 Dados referentes às adaptações de equipamentos e ferramentas.

\begin{tabular}{|c|c|c|c|c|}
\hline Equipamento & Adaptaçắo & Simllar no mercado & Dificuldades & Eficiência \\
\hline Carreta churumeira & $\begin{array}{l}\text { Fol feita uma adaptaçăo om "T" utilizando partes do } \\
\text { defletor central original para facilitar adubaçăo no } \\
\text { sistema radicular das plantas }\end{array}$ & Produtor desconhece & $\begin{array}{l}\text { Soldar o "T'" galvanizado no } \\
\text { local do defletor original }\end{array}$ & $\begin{array}{l}\text { Alta, embora a pressăo năo seja } \\
\text { muito adequada para adubacăo em } \\
\text { desnnlvel }\end{array}$ \\
\hline $\begin{array}{l}\text { Microtrator Tobatta com bico } \\
\text { riscador }\end{array}$ & $\begin{array}{l}\text { Foi foita uma adaptaçắo com a colocaçắo de um bico } \\
\text { riscador (bico de arado reduzido) para ricar cantelros. } \\
\text { Outra adaptaçăo semelhante fol feita colocando } 2 \\
\text { bicos riscadores para capinar feijăo }\end{array}$ & Produtor desconhece & $\begin{array}{l}\text { Regulagem de altura; haste } \\
\text { frágll - problema com dureza } \\
\text { do ferro (entorta ou quebra) }\end{array}$ & $\begin{array}{l}\text { Boa. Foi feita nova adaptaçăo para } \\
\text { capina do feijăo com dols bicos e } \\
\text { neste caso houve economia de } \\
\text { tempo e mâo-de-obra }\end{array}$ \\
\hline $\begin{array}{l}\text { Alças removiveis para caixad } \\
\text { plásticas }\end{array}$ & $\begin{array}{l}\text { Alças feltas com pedaços de cano de pve e } \\
\text { esquadrias de alumínio. Se adaptam perfeitamente às } \\
\text { caixas plásticas }\end{array}$ & 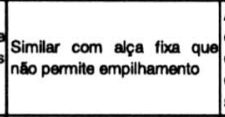 & $\begin{array}{l}\text { As calxas malores que são } \\
\text { de material reciclado, } \\
\text { deformam com o peso } \\
\text { durante a colheita e a alça } \\
\text { se solta }\end{array}$ & Boa para a maioria das caixas \\
\hline Motoserra com hélice de barco & $\begin{array}{l}\text { Hélice de barco fol adaptada à motoserra e colocada } \\
\text { sobre cavalete } \mathrm{p} / \text { misturar churume }\end{array}$ & Produtor desconhece & $\begin{array}{l}\text { Nenhuma, inspirou-se nos } \\
\text { tratamentos de esgoto }\end{array}$ & $\begin{array}{l}\text { Muito boa, pois antes mexia } 0 \\
\text { tanque com rodo }\end{array}$ \\
\hline Peneira com motor elétrico & $\begin{array}{l}\text { Foi adaptado motor elétrico à peneira de húmus of } \\
\text { feijăo }\end{array}$ & simillar para húmus e fej]ấo & $\begin{array}{l}\text { Adaptar saco para recolher o } \\
\text { material peneirado; ruido } \\
\text { elevado; } 3 \text { malhas diferentes }\end{array}$ & Boa \\
\hline Aerador -fermentador & 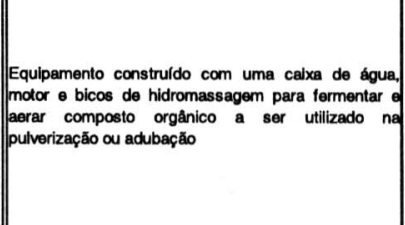 & Fermentador Agro-vortex & $\begin{array}{l}\text { Encontrar bico eficiente para } \\
\text { todo o sisterma; tiveram que } \\
\text { colocar entâo } 4 \text { bicos de } \\
\text { hidromassagem e motor } \\
\text { com potêncla de } 1 \text { cavalo }\end{array}$ & 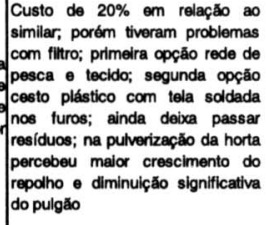 \\
\hline $\begin{array}{l}\text { Forno de barro com chaminé ent } \\
\text { ângulo }\end{array}$ & $\begin{array}{l}\text { Fol feita construção de barro em formato de forno com } \\
\text { chaminá em ângulo para produçấo de ácido } \\
\text { pirolenhoso }\end{array}$ & Produtor desconhece & 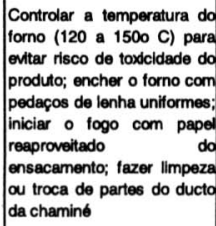 & $\begin{array}{l}0 \\
0 \\
0 \\
0 \\
0 \\
0 \\
0\end{array}$ \\
\hline
\end{tabular}

O cultivo orgânico de frutas pressupõe várias tarefas manuais - algumas delas dificilmente realizadas no manejo convencional - necessárias para atender às exigências técnicas do manejo orgânico. Essas tarefas são derivadas dos procedimentos técnicos especificados para a produção vegetal - no manejo e na conservação do solo e da água; no manejo da cultura; na nutrição vegetal; no manejo de pragas, doenças e plantas invasoras; na colheita, no armazenamento, no transporte e na comercialização. Algumas das tarefas manuais são apontadas como muito fatigantes pelos agricultores da propriedade em estudo, tais como a capina e a roçada manual, o transporte de esterco para compostagem e o ensacamento de frutas. Apesar de a tarefa de ensacar frutos não ser exclusiva do sistema de produção orgânico, ela ocorre com bastante freqüência para atender aos procedimentos técnicos acima especificados. Na propriedade estudada, a tarefa de ensacar frutas foi destacada por todos os integrantes da produção como desgastante, exercida sob pressão devido ao tempo em postura desconfortável, mui- tas vezes durante toda a jornada de trabalho, com movimentos repetitivos dos membros superiores, freqüentemente mantidos acima do nível dos ombros devido à altura dos galhos das árvores. Durante as observações sistemáticas da atividade do ensacamento de frutas, verificou-se que em média são ensacados de duzentos e cinqüenta a trezentos frutos por pé, sendo que em safras anteriores já se ensacaram mais de quinhentos frutos. $O$ ensacamento compreende três etapas: a preparação, o raleio e o ensacamento propriamente dito. Durante a atividade, o operador toma decisões quanto: ao modo de "atacar" a árvore de frutas, neste caso específico, a goiabeira; à quantidade de material a ser utilizado; ao equipamento que vai ser usado para alcançar as goiabas (gancho, escada ou ambos); e à forma de efetuar o raleio. Ainda é preciso decidir como resolver os incidentes que ocorrem, principalmente na etapa de ensacamento, dentro do tempo disponível para realização do trabalho. Esses incidentes podem estar relacionados ao saco de papel utilizado para ensacar as frutas ou ao grampeador, 
utilizado para o fechamento do mesmo. $\mathrm{Na}$ Tabela 2 encontra-se uma amostra dos incidentes que ocorreram durante 0 ensacamento em 17 minutos de observação. Verificou-se a ocorrência de vinte e um incidentes, sendo a "falha do grampeador" o incidente mais freqüente. Vale ressaltar que cada tipo de incidente demanda uma ação de recuperação por parte do operador, o que, além de diminuir sua produtividade, exige uma permanência maior em posturas desconfortáveis.

Tabela 2 Total de incidentes no ensacamento de frutas - 12/08/2003.

\begin{tabular}{|c|c|c|}
\hline \multicolumn{3}{|c|}{$\begin{array}{l}\text { DATA: } 12 / 08 / 03 \\
\text { HOR^RIO: das } 10 \mathrm{~h} 30 \text { às } 10 \mathrm{~h} 47\end{array}$} \\
\hline TIPO & DESCRIC̣ÃO DO INCIDENTE & TOTAL \\
\hline 1 & sacos de papel virados & 2 \\
\hline 2 & sacos de papel descolados & 0 \\
\hline 3 & sacos de papel grudados & 2 \\
\hline 4 & queda de sacos de papel & 2 \\
\hline 5 & travamento do grampeador & 2 \\
\hline 6 & falha do grampeador & 1 \\
\hline
\end{tabular}

Devido à altura dos pés de goiaba, o operador raramente consegue ensacar frutas sem o uso de equipamento auxiliar, que facilita $o$ alcance das frutas. Além da escada, que precisa ser usada na maior parte do tempo, 0 operador utiliza ainda um gancho desenvolvido e provido por ele para arquear cada galho, permitindo o alcance das frutas e, ao mesmo tempo, mantendo as duas mãos livres para realizar o trabalho, visto que o gancho é mantido preso em um dos pés (Figura 6).

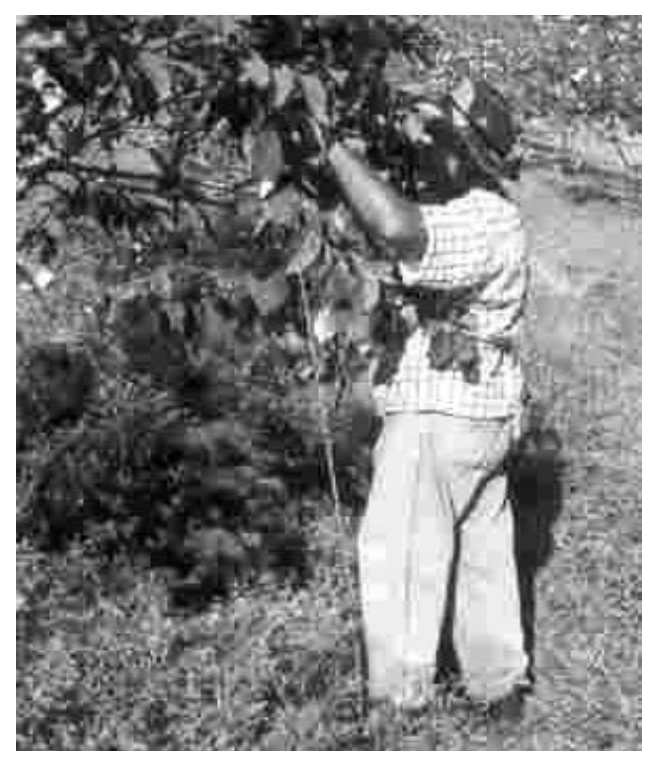

Figura 6 Operador usando gancho no ensacamento de frutas.
O esforço feito por um dos membros inferiores, ao sustentar o gancho para manter - galho arqueado, é proporcional ao tamanho e à espessura do mesmo e à carga existente de frutas. $O$ operador refere que "os galhos muito antigos são muito pesados", - que torna a utilização do gancho desgastante, ocasionando "fadiga ou dor na perna". Algumas vezes é necessário que o operador utilize a escada e o gancho concomitantemente para poder alcançar todos os frutos dos galhos mais altos (Figura 7).

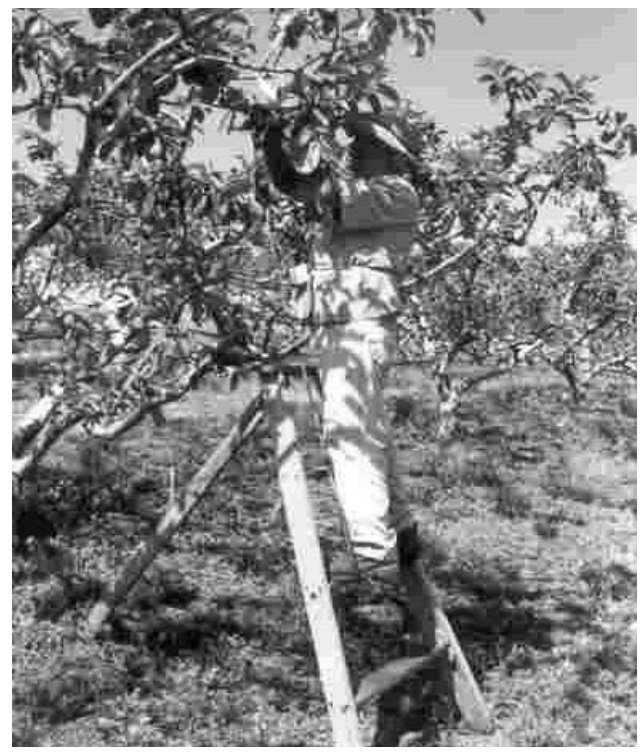

Figura 7 Operador usando gancho e escada no ensacamento de frutas. 
Devido à altura das goiabeiras, o operador trabalha a maior parte do pomar utilizando a escada, o que faz com que ele demore mais tempo para ensacar e ainda exerça um esforço considerável para se manter equilibrado na escada em um terreno com inclinação de $5 \%$ a $10 \%$. Além disso, o operador exerce esforço ao subir e descer da escada e ao deslocá-la ao redor das árvores e ao longo do pomar.

As Figuras 8 e 9 mostram cronologicamente a postura dos membros superiores do operador durante o ensacamento de goiabas em função da etapa de trabalho. Observa-se que o operador trabalha a maior parte do tempo com os membros superiores acima do nível dos ombros, sendo que, na Figura 9, a repetitividade de movimentos aparece de forma mais acentuada. Essa condição pode representar um risco para a saúde do operador, visto que as posturas desconfortáveis e os movimentos repetitivos são associados ao aparecimento de problemas musculares e esqueléticos (Malchaire, 1998; Pinzke, 1997; Kuorinka \& Forcier, 1995).

PRIMEIRO MINUTO DE TRABALHO (09:50:00 às 9:51:00H)

Filmagem dia 19/08/2003

Intervalo - Galho: 9:50:00H às 9:59:32 H

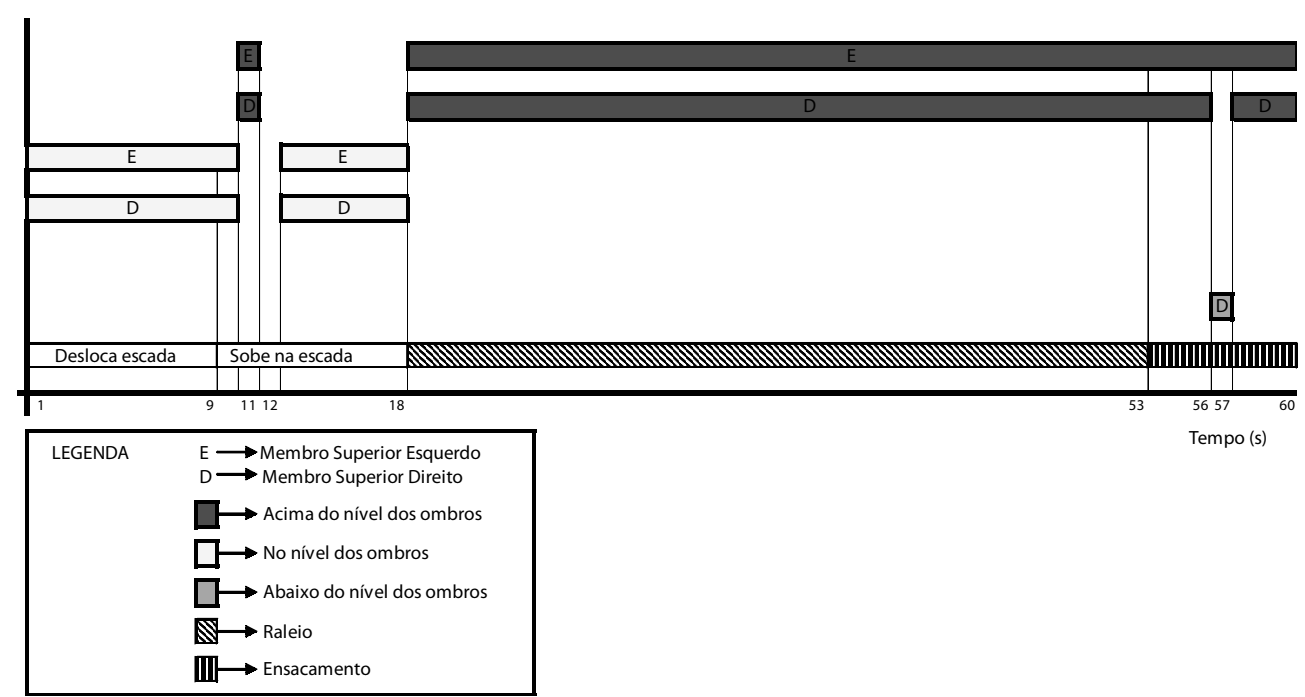

Figura 8 Cronologia da atividade do ensacamento de frutas (primeiro minuto).

MINUTO INTERMEDIÁRIO DE TRABALHO ( 9:54:14H às 9:55:14H)

Filmagem dia 19/08/2003

Intervalo - Galho: 9:50:00H às 9:59:32 H

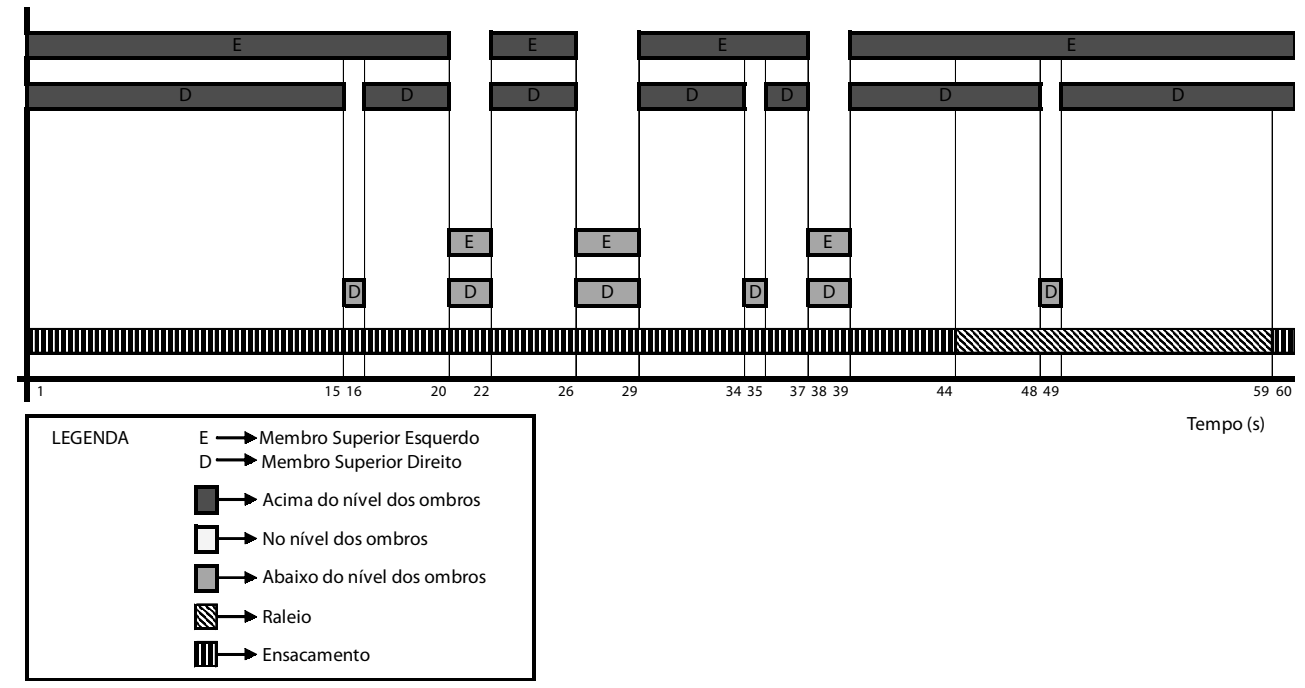

Figura 9 Cronologia da atividade do ensacamento de frutas (minuto intermediário). 


\section{Conclusões}

A agricultura orgânica compreende atividades complexas relacionadas à variabilidade de cultivos, à carência de apoio e suporte técnico disponível, levando os agricultores a trabalhar na base de tentativa e erro, à falta de tecnologia apropriada, determinando adaptações de ferramentas, equipamentos e materiais, à utilização de um grande número de pessoas para fazer tarefas manuais em substituição ao uso de praguicidas convencionais e à mecanização, à certificação da produção orgânica que demanda tarefas adicionais.

Cada tipo de cultivo envolve uma série de etapas e cada uma delas demanda uma ampla variedade de tarefas. Isso traz uma exigência muito grande para os agricultores em termos de conhecimentos técnicos específicos e também na gestão de tantas variáveis da produção. Na produção orgânica, a propriedade deve ser vista de forma sistêmica, sobretudo no preparo do solo e no controle de plantas invasoras, pragas e doenças. Isso acarreta uma necessidade de monitoramento constante da produção e a gestão das informações levantadas, sendo mais um fator de complexidade no trabalho. Algumas dificuldades relacionadas ao processo de certificação e a sua manutenção também interferem diretamente no trabalho de gestão da produção orgânica, pois envolvem custos, adequações da propriedade para atender às exigências das normas e tarefas adicionais, principalmente administrativas.

\section{Referências Bibliográficas}

ALVES FILHO, J. P. Segurança e Saúde do Trabalhador Rural: Aspectos Gerais. Boletim Orgânica, São Paulo, v.1, n.1, pp. 11-15, novembro, 1999.

CHAIM, C. Saúde! Mercado de Produtos Orgânicos Cresce 50\% ao Ano e Desperta o Interesse de Empresas Estrangeiras. ISTOÉ, Brasil, Economia \& Negócios, pp .72- 73, 04 setembro de 2002.

DAROLT, M. R. Agricultura Orgânica: Inventando o Futuro. Londrina: IAPAR, 2002.

EHLERS, E. Agricultura Sustentável - Origens e Perspectivas de um Novo Paradigma. Guaíba: Agropecuária, 1999.
É importante destacar que algumas das tarefas manuais que aparecem com maior freqüência no cultivo orgânico podem colocar em risco a saúde dos agricultores por demandarem esforço físico considerável, posturas desconfortáveis e movimentos repetitivos, além da questão da pressão por tempo, que podem ocasionar o aparecimento de distúrbios musculares e esqueléticos.

No ensacamento de frutas, por exemplo, a posição e a altura do galho podem determinar as posturas físicas desconfortáveis adotadas pelo operador, que, mesmo com auxílio de equipamentos para alcançar os frutos, permanece a maior parte do tempo com os membros superiores elevados acima do nível dos ombros. Podas que privilegiem as necessidades da tarefa de ensacamento podem minorar o problema.

A falta de tecnologia apropriada foi evidenciada pela descrição de muitos equipamentos, ferramentas e materiais adaptados. Quanto à carência de estudos e tecnologia apropriada para o manejo orgânico, sugere-se que os especialistas técnicos, tanto da área agrícola quanto da ergonomia, unamse no desenvolvimento de pesquisas e projetos específicos que visem melhorar a condição de trabalho dos agricultores a fim de assegurar que este segmento possa contribuir não somente para a sustentabilidade da exploração agrícola, mas também para a saúde dos trabalhadores envolvidos.
GUÉRIN, F. et al. Compreender o Trabalho para Transformá-lo: a Prática da Ergonomia. São Paulo: Edgard Blücher, 2001.

JAFRY, T. \& O'Neill, D. H. The Application of Ergonomics in Rural Development: a Review. Applied Ergonomics, UK, v. 31, pp. 263-268, 2000.

KUORINKA, I. \& FORCIER, L. Work Related Musculoskeletal Disorders (WMSDs): A Reference Book for Prevention. London: Taylor \& Francis, 1995.

MALCHAIRE, J. Lesiones de Miembros Superiores por Trauma Acumulativo Estratégia 
de Prevencion. Universidad Católica de Lovaina, Unidad de Higiene y Fisiologia del Trabajo. Bélgica, 1998.

ORMOND, J. G. P. et al. Agricultura Orgânica: Quando o Passado é Futuro. BNDES/2001. Disponível em: <fttp: //www.ibd.com.br>. Acesso em 28 de junho de 2002.
PINZKE, S. Observational Methods for Analyzing Working Postures in Agriculture. Journal of Agricultural Safety and Health. Sweden, v.3, n.3, pp. 169-194, 1997.

WISNER, A. A Inteligência no Trabalho: Textos Selecionados de Ergonomia. São Paulo: Fundacentro, 1994. 